\title{
Low consumption of fruit and vegetables and risk of chronic disease: a review of the epidemiological evidence and temporal trends among Spanish graduates
}

\author{
Miguel Á Martínez-González*, Carmen de la Fuente-Arrillaga, Cristina López-del-Burgo, \\ Zenaida Vázquez-Ruiz, Silvia Benito and Miguel Ruiz-Canela \\ Department of Preventive Medicine and Public Health, Medical School and Clinic, University of Navarra, \\ Irunlarrea 1, 31080 Pamplona, Navarra, Spain
}

Submitted 13 May 2011: Accepted 7 September 2011

\begin{abstract}
Objective: To review the evidence on the association between fruit and vegetable $(\mathrm{F} \& \mathrm{~V})$ consumption and risk of chronic disease, and to assess trends in the prevalence of low F\&V consumption.

Design: Systematic review and cross-sectional analyses of a Mediterranean cohort. Setting: The Seguimiento University of Navarra (SUN) project (Spanish dynamic cohort of graduates).

Subjects: A systematic review of prospective studies aimed to assess the relationship between fruit and/or vegetables consumption and chronic disease incidence was conducted. We also assessed 18457 university graduates (59.4\% women; mean age $=39$ (SD 12) years) enrolled in a dynamic cohort with permanently open recruitment. Baseline data were collected between 1999 and 2010 using a validated 136-item FFQ. Four definitions for low F\&V consumption were used ( $<400 \mathrm{~g} / \mathrm{d},<200 \mathrm{~g} / 4184 \mathrm{~kJ}(1000 \mathrm{kcal})$ per d, $\leq 2$ servings/d and $\leq 1 \mathrm{serving} / \mathrm{d})$. Multivariate-adjusted cross-sectional associations between the prevalence of low $\mathrm{F} \& \mathrm{~V}$ consumption and the year of recruitment were estimated.

Results: The systematic review found that a high F\&V consumption is inversely associated with CVD incidence and mortality. This association is not so clear for cancer. Inconsistent findings have been reported for diabetes. In all, 13\% of participants in the SUN cohort did not meet the goal of consuming at least $400 \mathrm{~g} / \mathrm{d}$ of F\&V and $2 \cdot 1 \%$ of them did not reach $>1$ serving/d. Between 1999 and 2010 the consumption of F\&V significantly increased.

Conclusions: Even among health-conscious university graduates, low F\&V consumption is fairly prevalent. Although the temporal trends suggest an improvement, preventive strategies addressed to increase F\&V consumption are needed.
\end{abstract}

Chronic non-communicable diseases account for $60 \%$ of all deaths worldwide ${ }^{(1)}$. Sufficiently high consumption of fruit and vegetables $(\mathrm{F} \& \mathrm{~V})$ has been related to a lower risk of major chronic disease and eating at least five servings of $\mathrm{F} \& \mathrm{~V}$ per day has been extensively recommended to promote longevity and to reduce the risks of CVD and cancer $^{(2-4)}$. Moreover, low F\&V consumption has been ranked among the twelve leading risk factors responsible for avoidable mortality in the USA ${ }^{(5)}$ and has been reported to be responsible for $2 \cdot 7$ million deaths globally ${ }^{(4)}$.

Our aim was to review the available epidemiological evidence on F\&V consumption and the risk of major chronic disease and to appraise the temporal trend in the prevalence of low F\&V consumption in a Mediterranean cohort of university graduates.

\section{Methods}

\section{Literature review}

We searched electronic databases (1980-2009) for published prospective studies that assessed the relationship between the consumption of fruit and/or vegetables and the incidence or mortality from CVD, cancer or diabetes and included a quantitative assessment of $\mathrm{F} \& \mathrm{~V}$ intake.

\section{The Seguimiento University of Navarra prospective cobort}

The Seguimiento University of Navarra (SUN) cohort is a Mediterranean epidemiological study with a prospective design. All participants are university graduates. The SUN cohort is patterned after the models of the Nurses' Health 
Study or the Health Professionals Follow-up Study, which are composed only of highly educated participants, thus ensuring a more complete follow-up and a better quality of self-reported information. A major difference of the SUN cohort is that the recruitment is permanently open, because a dynamic design has been chosen for this cohort. New participants have been admitted every year since 1999, thus allowing for estimation of temporal trends in lifestyle and food habits of recruited participants. Extensive information about the methods, objectives and design of this cohort has been published previously ${ }^{(6-8)}$. Information on exposure was gathered by mailed questionnaires at baseline. Outcomes were assessed through follow-up questionnaires collected biennially.

A previously validated and extensively used 136-item $\mathrm{FFQ}^{(9-11)}$ was collected at baseline together with a wide array of information about sociodemographic characteristics, anthropometric variables, lifestyles and healthrelated habits ${ }^{(8)}$. The baseline questionnaire included 554 items ${ }^{(8)}$. The validity of self-reported information has been assessed in specific studies using subsamples of the SUN cohort ${ }^{(12-15)}$.

Up to May 2010, 20426 participants had been admitted to the SUN cohort and had completed their baseline evaluation. From them, we excluded participants who reported very low or very high values for total energy intake according to predefined limits ${ }^{(16)}$, because they were more likely to have failed to properly complete the questionnaire $(<3347 \mathrm{~kJ}(<800 \mathrm{kcal}) / \mathrm{d}$ in men or $<2092 \mathrm{~kJ}$ $(<500 \mathrm{kcal}) / \mathrm{d}$ in women or $>16736 \mathrm{~kJ}(>4000 \mathrm{kcal}) / \mathrm{d}$ in men or $>14644 \mathrm{~kJ}(>3500 \mathrm{kcal}) / \mathrm{d}$ in women) ( $n$ 1969). Therefore, 18457 participants were included in the following analyses.

The present study was approved by the Institutional Review Board of the University of Navarra. Voluntary completion of the first questionnaire was considered to imply informed consent.

\section{Definition of low fruit and vegetable consumption}

The FFQ included sixteen items for fruits and eleven items for vegetables (plus potatoes and French fries, which were excluded). Each item in the FFQ included a typical portion size $^{(9-11)}$. Daily food consumption was estimated by multiplying the portion size by the consumption frequency, for each food item (nine options ranging from never or almost never to six or more times per day). A team of trained dietitians updated the nutrient databank using the latest available information included in food composition tables for Spain. We used three alternative operative definitions for low F\&V consumption: (i) $\leq 400 \mathrm{~g} / \mathrm{d}$; (ii) $\leq 200 \mathrm{~g} / 4184 \mathrm{~kJ}$ $(1000 \mathrm{kcal}) / \mathrm{d}$; and (iii) $\leq 2$ servings/d. The operative definition of very low F\&V consumption was $\leq 1$ serving/d.

\section{Statistical methods}

Differences in sociodemographic or behavioural characteristics of participants according to the period of recruitment were estimated with one-way ANOVA or Pearson's $\chi^{2}$.

Logistic regression models were fit with each of the definitions for low or very low F\&V consumption as outcome. Potential confounders included in all models were age, sex and the higher educational status achieved by the participant (four levels: only college, postgraduate school, masters degree, doctoral degree). Tests of linear trend were conducted using the likelihood ratio test with the calendar year of entering the cohort introduced as a continuous independent variable and adjusting for the potential confounders. All these analyses were repeated after stratifying by sex. In sensitivity analyses, we also additionally adjusted for baseline BMI (continuous), marital status (married/others), current smoking at baseline, leisure-time physical activity (METS-h/week, continuous) and alcohol consumption (g/d, continuous).

All $P$ values presented are two-tailed; $P<0.05$ was considered statistically significant. The Statistical Package for the Social Sciences software package for Windows version 15.0 (SPSS Inc., Chicago, IL, USA) was used for statistical analyses.

\section{Results}

\section{Literature review}

Table 1 shows the results of some recently published meta-analyses on F\&V consumption and the risk of CVD. All of them included only prospective cohort studies. A pooled analysis of eleven cohort studies conducted by Pereira et $a l .^{(17)}$ found that fruit fibre was inversely associated with the incidence of CHD events and also with CHD mortality. Null associations were found for vegetable fibre. Subsequently, two meta-analyses on F\&V intake and CHD were published ${ }^{(18,19)}$. The meta-analysis conducted by Dauchet et al. ${ }^{(18)}$ found stronger inverse associations for fruit than for vegetable intake. The meta-analysis by He et al. ${ }^{(19)}$ showed an inverse dose-response trend.

In addition to the traditional narrative review by Ness and Powles ${ }^{(20)}$, two recent meta-analyses of fruit or vegetable consumption and stroke risk have been published ${ }^{(21,22)}$. The meta-analysis by Dauchet ${ }^{(21)}$ showed that stroke risk was reduced by $11 \%$ for each additional serving/d of fruit and by a non-significant $3 \%$ for each additional serving/d of vegetables. The estimates of relative risk in the meta-analysis by $\mathrm{He}$ et $a l^{(22)}$ were 0.72 (95\% CI 0.66, 0.79) for fruits and 0.81 (95\% CI 0.72, 0.90) for vegetables for the comparison between the highest ( $>5$ servings/d) and the lowest $(<3$ servings/d) intake categories. There were no statistically significant differences in the risk of stroke when the intermediate category of vegetable consumption was compared with the lowest category of consumption. Some meta-analyses suggested the possibility of publication bias (some small studies with null results might have remained unpublished), but 
the likely magnitude of this bias was weak (Table 1). Stronger protection by fruit than for vegetables against CVD is also in agreement with other recent cohort studies, not included in the above cited meta-analyses, such as two large Japanese cohorts, ${ }^{(23,24)}$ the Shanghai Women's Health Study ${ }^{(25)}$ and the Finnish Mobile Clinic cohort ${ }^{(26)}$, but not with another Japanese cohort assessing only fatal cases of $\mathrm{CVD}^{(27)}$ or a recent cohort in France and Northern Ireland that found inverse associations for F\&V and CVD only among smokers ${ }^{(28)}$. However, for the combined consumption of $\mathrm{F} \& \mathrm{~V}$, most cohort studies, also those not included in the meta-analyses, showed inverse significant associations.

Table 2 shows the available results of two metaanalyses $^{(29,30)}$ on the relationship between F\&V consumption and type 2 diabetes incidence. Although an inverse trend was suggested by some individual studies and the consumption of green leafy vegetables was inversely associated with stroke risk in one of them ${ }^{(24)}$, the overall results were largely non-significant.

The largest study conducted to assess the relationship between F\&V consumption and cancer risk included nearly 400000 European men and women followed up for 9 years but found only a weak reduction in risk (4\%) in spite of observing approximately 30000 cancers in total $^{(31)}$. Previous beliefs in strong protection against cancer attributed to F\&V consumption were overly optimistic and were based mainly on results from casecontrol studies with a strong potential for bias ${ }^{(32,33)}$. A comprehensive review of case-control and cohort studies reported that in prospective cohort studies, not so prone to biases, the risk reduction was significant only for cancers of the lung and bladder, and only for fruit ${ }^{(33)}$. A pooled analysis of thirteen prospective studies also found an inverse association for renal cell cancer ${ }^{(34)}$. A recent comprehensive assessment of the available evidence on the relationship between the consumption of F\&V and cancer risk does not support a strong benefit ${ }^{(35)}$.

\section{Fruit and vegetable consumption in the participants of the Seguimiento University of Navarra cobort}

Table 3 shows that the characteristics of participants entering the SUN cohort during different periods (1999-2010) were not completely homogeneous. However, in spite of the statistically significant results for all variables except leisure-time physical activity, the absolute magnitude of the differences was small.

The prevalence of low or very low F\&V consumption was always higher in men than in women, regardless of the definition used (Table 4). The temporal trend suggested that the adequate $F \& V$ consumption improved with time in university graduates entering this cohort. All tests for linear trend were statistically significant, suggesting that with each calendar year the prevalence of low fruit consumption was reduced by approximately $2-11 \%$. 


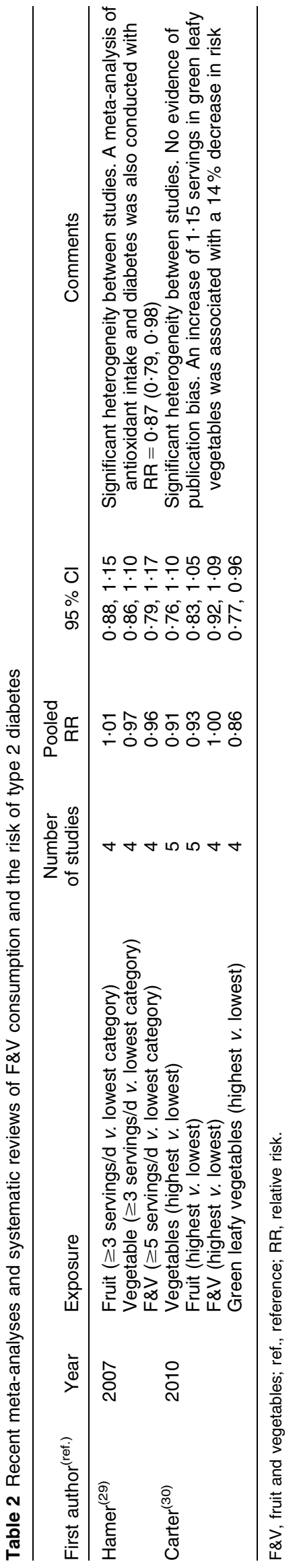

However, when the first definition of low F\&V consumption $(\leq 400 \mathrm{~g} / \mathrm{d})$ was used among men, the results only approached statistical significance $(P=0 \cdot 06)$. The results were similar and remained statistically significant (data not shown) after additionally adjusting the models for baseline BMI, marital status, current smoking at baseline, leisuretime physical activity and alcohol consumption.

\section{Discussion}

The health promotion advice to select diets largely based on plant foods and to increase the consumption of $F \& V$ has not changed in the past 50 years ${ }^{(36)}$. However, the actual global levels of F\&V consumption are far from optimal $^{(4,5,35)}$. Whereas the potential benefits of $\mathrm{F} \& \mathrm{~V}$ against cancer incidence are only weak and restricted to certain types of cancer, the results of large cohort studies consistently provide enough evidence to support strong benefits against CVD. In particular, fruit consumption is associated with relative reductions in risk higher than $25 \%$ for stroke and higher than 15\% for CHD. The commonly proposed goal of consuming at least five portions (or at least $400 \mathrm{~g}$ ) of vegetables and fruits per day ${ }^{(4,35)}$ to reduce the risk of CHD or stroke is well supported by prospective epidemiological evidence ${ }^{(37)}$. There is, however, a need for further evidence regarding diabetes prevention.

The more recent results of cohort studies, as compared with previous case-control studies, provide only weak evidence of the association of $F \& V$ consumption with reduced cancer risk. The inconsistencies between cohort and case-control studies on this issue may be related to recall and selection biases in case-control studies ${ }^{(33)}$. A lower participation rate among controls than among cases is very likely in most case-control scenarios. Control subjects who agree to participate are typically very health conscious persons who tend to consume more F\&V than those who did not choose to participate ${ }^{(32)}$. This would lead to an apparent inverse association of F\&V with cancer in case-control studies even if that association is not true. These false benefits might be further exaggerated if the groups of control and cases differentially recall or report their past diets due to the fact that many cases recently received a dismal diagnosis, whereas controls were not under this psychological impact.

On the other hand, an underestimation of a true inverse association between $F \& V$ consumption and the risk of chronic disease may happen in any epidemiological study because of imprecise dietary measurements, regressiondilution bias $^{(38)}$ or limited between-subjects variability in F\&V consumption ${ }^{(33)}$. Some degree of non-differential misclassification (measurement error) is unavoidable in nutritional epidemiology and may account for losing the ability to detect some real associations if they are not strong enough. However, in a large cohort study that 
Table 3 Characteristics of graduates entering the SUN cohort according to the recruitment period (1999-2010)

\begin{tabular}{|c|c|c|c|c|c|c|c|c|c|c|c|}
\hline \multirow[b]{2}{*}{ Variable } & \multicolumn{2}{|c|}{$\begin{array}{c}1999-2001 \\
(n 6624)\end{array}$} & \multicolumn{2}{|c|}{$\begin{array}{c}2002 \\
(n 3091)\end{array}$} & \multicolumn{2}{|c|}{$\begin{array}{c}2003-2004 \\
(n \text { 4036) }\end{array}$} & \multicolumn{2}{|c|}{$\begin{array}{c}2005-2007 \\
(n 3578)\end{array}$} & \multicolumn{2}{|c|}{$\begin{array}{c}2008-2010 \\
(n 1128)\end{array}$} & \multirow[b]{2}{*}{$P$ value } \\
\hline & Mean & SD & Mean & SD & Mean & SD & Mean & SD & Mean & SD & \\
\hline \% Women & \multicolumn{2}{|c|}{60} & \multicolumn{2}{|c|}{57} & \multicolumn{2}{|c|}{57} & \multicolumn{2}{|c|}{67} & \multicolumn{2}{|c|}{51} & $<0.001$ \\
\hline Age (years) & 37 & 13 & 37 & 11 & 42 & 12 & 40 & 12 & 39 & 14 & $<0.001$ \\
\hline University degreet & & & & & & & & & & & \\
\hline$\%$ Only college & \multicolumn{2}{|c|}{35} & \multicolumn{2}{|c|}{28} & \multicolumn{2}{|c|}{39} & \multicolumn{2}{|c|}{16} & \multicolumn{2}{|c|}{19} & $<0.001$ \\
\hline$\%$ Masters degree & \multirow{2}{*}{\multicolumn{2}{|c|}{$\begin{array}{r}7 \\
10\end{array}$}} & \multirow{2}{*}{\multicolumn{2}{|c|}{$\begin{array}{r}8 \\
11\end{array}$}} & \multicolumn{2}{|c|}{4} & \multicolumn{2}{|c|}{10} & \multicolumn{2}{|c|}{18} & \\
\hline$\% \mathrm{PhD}$ & & & & & & & & & \multicolumn{2}{|c|}{16} & \\
\hline$\%$ Married & \multicolumn{2}{|c|}{45} & \multicolumn{2}{|c|}{51} & \multicolumn{2}{|c|}{61} & \multicolumn{2}{|c|}{$\begin{array}{l}10 \\
53\end{array}$} & & & $<0.001$ \\
\hline$\%$ Current smokers & \multicolumn{2}{|c|}{25} & \multicolumn{2}{|c|}{25} & \multicolumn{2}{|c|}{18} & \multicolumn{2}{|c|}{18} & \multicolumn{2}{|c|}{17} & $<0.001$ \\
\hline BMl $\left(\mathrm{kg} / \mathrm{m}^{2}\right)$ & $23 \cdot 3$ & $3 \cdot 4$ & $23 \cdot 3$ & $3 \cdot 5$ & $24 \cdot 2$ & $3 \cdot 5$ & $23 \cdot 6$ & $3 \cdot 8$ & $23 \cdot 7$ & $3 \cdot 6$ & $<0.001$ \\
\hline Alcohol consumption (g/d) & $6 \cdot 5$ & $10 \cdot 1$ & $6 \cdot 6$ & $9 \cdot 8$ & $7 \cdot 5$ & $11 \cdot 6$ & $6 \cdot 7$ & $10 \cdot 1$ & $6 \cdot 8$ & $9 \cdot 3$ & $<0.001$ \\
\hline Physical activity (METS-h/week) & 24 & 21 & 24 & 23 & 25 & 23 & 24 & 22 & 25 & 23 & 0.08 \\
\hline
\end{tabular}

METS, metabolic equivalents during leisure time.

Values are mean and standard deviation unless otherwise stated.

*The $\chi^{2}$ or one-way ANOVA.

tPercentages do not add $100 \%$ because there is a fourth category (postgraduates) between 'only college' and 'masters degree'.

Table 4 Trends in the prevalence of low F\&V consumption among graduates entering the SUN cohort (1999-2010)

\begin{tabular}{|c|c|c|c|c|c|c|c|c|c|c|c|c|c|}
\hline \multirow[b]{4}{*}{ Total } & \multirow[b]{4}{*}{$n$} & \multicolumn{9}{|c|}{ Low F\&V consumption } & \multirow{2}{*}{\multicolumn{3}{|c|}{$\begin{array}{c}\text { Very low consumption } \\
\leq 1 \text { serving/d }\end{array}$}} \\
\hline & & \multicolumn{3}{|c|}{$\leq 400 \mathrm{~g} / \mathrm{d}$} & \multicolumn{3}{|c|}{$\leq 200 \mathrm{~g} / 1000 \mathrm{kcal} / \mathrm{d}$} & \multicolumn{3}{|c|}{$\leq 2$ servings/d } & & & \\
\hline & & \multicolumn{3}{|c|}{ Adjusted* } & \multicolumn{3}{|c|}{ Adjusted $^{*}$} & \multicolumn{3}{|c|}{ Adjusted* } & \multicolumn{3}{|c|}{ Adjusted ${ }^{*}$} \\
\hline & & $\%$ & OR & $95 \% \mathrm{Cl}$ & $\%$ & OR & $95 \% \mathrm{Cl}$ & $\%$ & OR & $95 \% \mathrm{Cl}$ & $\%$ & OR & $95 \% \mathrm{Cl}$ \\
\hline 1999-2001 & 6624 & $13 \cdot 6$ & $1 \cdot 00$ & Ref. & $19 \cdot 4$ & - & - & $10 \cdot 3$ & - & - & $2 \cdot 3$ & - & - \\
\hline 2002 & 3091 & $15 \cdot 2$ & $1 \cdot 08$ & $0 \cdot 95,1 \cdot 22$ & $20 \cdot 3$ & $1 \cdot 00$ & $0 \cdot 89,1 \cdot 11$ & $12 \cdot 1$ & $1 \cdot 16$ & $1 \cdot 01,1 \cdot 33$ & $2 \cdot 6$ & $1 \cdot 06$ & $0 \cdot 80,1 \cdot 40$ \\
\hline 2003-2004 & 4036 & $13 \cdot 1$ & 1.09 & $0.97,1 \cdot 23$ & $16 \cdot 8$ & 0.99 & $0 \cdot 89,1 \cdot 11$ & $9 \cdot 2$ & $1 \cdot 02$ & $0 \cdot 88,1 \cdot 17$ & $2 \cdot 2$ & 0.99 & $0 \cdot 76,1 \cdot 31$ \\
\hline 2005-2007 & 3578 & $8 \cdot 5$ & $0 \cdot 65$ & $0.57,0.75$ & $11 \cdot 2$ & $0 \cdot 60$ & $0.53,0.68$ & $5 \cdot 8$ & 0.58 & $0.49,0.68$ & $1 \cdot 4$ & $0 \cdot 61$ & $0.43,0.85$ \\
\hline 2008-2010 & 1128 & $14 \cdot 4$ & $1 \cdot 02$ & $0.84,1.23$ & $16 \cdot 7$ & 0.78 & $0.66,0.93$ & $9 \cdot 8$ & 0.90 & $0.73,1.12$ & $1 \cdot 3$ & 0.52 & $0.30,0.90$ \\
\hline Overall & 18457 & $12 \cdot 8$ & - & - & $17 \cdot 2$ & - & - & $9 \cdot 4$ & - & - & $2 \cdot 1$ & - & \\
\hline $\begin{array}{l}\text { Per } 1+\text { year } \\
P \text { for trend }\end{array}$ & & $<0.001$ & $\begin{aligned} & 0.97 \\
< & 0.001\end{aligned}$ & $0.95,0.98$ & $<0.001$ & $\begin{array}{c}0.94 \\
<0.001\end{array}$ & $0.93,0.96$ & $<0.001$ & $\begin{aligned} & 0.95 \\
< & 0.001\end{aligned}$ & $0.93,0.97$ & $<0.001$ & $\begin{array}{l}0.93 \\
0.001\end{array}$ & $0.89,0.97$ \\
\hline \multicolumn{14}{|l|}{ Men } \\
\hline 1999-2001 & 2674 & $18 \cdot 5$ & $1 \cdot 00$ & Ref. & $27 \cdot 4$ & $1 \cdot 00$ & Ref. & $13 \cdot 5$ & $1 \cdot 00$ & Ref. & $3 \cdot 0$ & $1 \cdot 00$ & Ref. \\
\hline 2002 & 1327 & $19 \cdot 4$ & $1 \cdot 02$ & $0 \cdot 86,1 \cdot 21$ & $27 \cdot 8$ & 0.95 & $0 \cdot 82,1 \cdot 11$ & $14 \cdot 5$ & $1 \cdot 06$ & $0 \cdot 88,1 \cdot 29$ & $2 \cdot 6$ & $0 \cdot 86$ & $0.57,1.29$ \\
\hline 2003-2004 & 1744 & $17 \cdot 3$ & $1 \cdot 09$ & $0 \cdot 92,1 \cdot 28$ & $23 \cdot 5$ & $1 \cdot 01$ & $0 \cdot 87,1 \cdot 17$ & $12 \cdot 1$ & $1 \cdot 05$ & $0 \cdot 87,1 \cdot 27$ & $2 \cdot 9$ & 1.09 & $0.75,1.59$ \\
\hline 2005-2007 & 1198 & $14 \cdot 4$ & $0 \cdot 80$ & $0.66,0.98$ & $18 \cdot 5$ & 0.68 & $0.57,0.81$ & $9 \cdot 6$ & $0 \cdot 73$ & $0.57,0.91$ & $2 \cdot 0$ & $0 \cdot 67$ & $0.41,1.09$ \\
\hline 2008-2010 & 554 & $16 \cdot 8$ & 0.93 & $0 \cdot 73,1 \cdot 20$ & $21 \cdot 3$ & 0.75 & $0.60,0.95$ & $11 \cdot 6$ & $0 \cdot 86$ & $0 \cdot 64,1 \cdot 15$ & $1 \cdot 4$ & 0.50 & $0.24,1.05$ \\
\hline Per $1+$ year & & & 0.98 & $0.95,1.00$ & - & 0.95 & $0.93,0.97$ & - & 0.96 & $0.94,0.99$ & - & 0.94 & $0.89,1.00$ \\
\hline$P$ for trend & & 0.006 & 0.06 & & $<0.001$ & $<0.001$ & & $0 \cdot 001$ & 0.01 & & 0.03 & 0.04 & \\
\hline \multicolumn{14}{|l|}{ Women } \\
\hline 1999-2001 & 3950 & $10 \cdot 4$ & $1 \cdot 00$ & Ref. & $14 \cdot 0$ & $1 \cdot 00$ & Ref. & $8 \cdot 1$ & 1.00 & Ref. & 1.9 & $1 \cdot 00$ & Ref. \\
\hline 2002 & 1764 & $12 \cdot 1$ & $1 \cdot 16$ & $0 \cdot 97,1.39$ & $14 \cdot 7$ & $1 \cdot 05$ & $0 \cdot 89,1 \cdot 24$ & $10 \cdot 3$ & $1 \cdot 28$ & $1 \cdot 05,1 \cdot 55$ & $2 \cdot 6$ & $1 \cdot 29$ & $0 \cdot 88,1 \cdot 88$ \\
\hline 2003-2004 & 2292 & $9 \cdot 9$ & $1 \cdot 10$ & $0 \cdot 92,1 \cdot 32$ & $11 \cdot 8$ & 0.97 & $0 \cdot 83,1 \cdot 14$ & $7 \cdot 0$ & 0.98 & $0 \cdot 80,1 \cdot 21$ & $1 \cdot 6$ & $0 \cdot 88$ & $0.59,1 \cdot 32$ \\
\hline 2005-2007 & 2380 & $5 \cdot 5$ & 0.53 & $0.43,0.65$ & $7 \cdot 4$ & 0.53 & $0.44,0.64$ & $3 \cdot 8$ & 0.46 & $0.36,0.59$ & $1 \cdot 1$ & 0.56 & $0.35,0.90$ \\
\hline 2008-2010 & 574 & $12 \cdot 0$ & $1 \cdot 14$ & $0 \cdot 86,1 \cdot 50$ & $12 \cdot 2$ & 0.83 & $0.63,1.09$ & $8 \cdot 2$ & 0.97 & $0 \cdot 70,1 \cdot 35$ & $1 \cdot 2$ & 0.53 & $0.23,1 \cdot 23$ \\
\hline Per $1+$ year & & & 0.95 & $0.93,0.98$ & - & 0.94 & $0.91,0.96$ & - & 0.93 & $0.91,0.96$ & - & 0.92 & $0.86,0.97$ \\
\hline$P$ for trend & & & $<0.001$ & & $<0.001$ & $<0.001$ & & -0001 & $<0.001$ & & 0.006 & 0.003 & \\
\hline
\end{tabular}

F\&V, fruit and vegetables; SUN cohort, Seguimiento University of Navarra cohort; Ref., referent category.

Multivariate-adjusted for age, sex (in the models including men and women) and educational level.

observed no association between F\&V and total cancer, a $30 \%$ lower incidence of CHD or stroke was found for $\geq 5$ servings $/ \mathrm{d} v \cdot<1 \cdot 5$ servings $/ \mathrm{d}^{(39)}$. It is revealing that in the same cohort, with identical potential for measurement errors and with the same between-subjects variability in intake, contrasting results were observed for cancer and for CVD. That study strongly supported that the benefits of F\&V accrue mainly because of their effects in cardiovascular protection but not so much because of their cancer preventive effects.
In summary, the benefits of F\&V consumption for cardiovascular health are well substantiated by empirical epidemiological research. As CVD is the leading cause of global mortality, the promotion of F\&V consumption represents a priority for global public health. In this context, the assessment of trends among highly educated subjects might be important because of the potential exemplary role that these sectors of the population with higher levels of education may play in achieving behavioural changes in society at large. Their lifestyles 
tend to be eventually adopted by the rest of the society. The assessment of trends among university graduates is a uniquely appropriate setting to provide the knowledge to design adequate intervention strategies to enhance the adoption of healthy eating habits ${ }^{(40,41)}$.

In our Mediterranean cohort of university graduates (the SUN project), we found that the prevalence of adequate consumption of $F \& V$ has recently increased in Spanish university graduates, with a highly significant trend for improvement. This improvement might be related to better information and to successful public health efforts to promote a healthy diet in Spain. Sectors of the population with a higher educational level might be more easily reached by these efforts and might be more likely to adopt healthier diets.

Our study may have some potential limitations. A potential caveat is related to possible unmeasured confounders, as we only adjusted for age, sex and education. Some other baseline characteristics of recruited participants for this cohort might have changed during the assessment period (1999-2010). However, additional adjustment for potentially important known confounders (BMI, alcohol intake, smoking and physical activity) did not substantially change the results with respect to the analyses presented in the tables. In fully adjusted models, the $P$ values for linear trend strongly suggested a decreasing trend for low F\&V consumption during the assessment period $(P=0.001$ for $\leq 400 \mathrm{~g} / \mathrm{d} ; P<0.001$ for $\leq 200 \mathrm{~g} / 4184 \mathrm{~kJ}(1000 \mathrm{kcal}) / \mathrm{d} ; P<0 \cdot 001$ for $\leq 2$ servings $/ \mathrm{d}$; $P=0.002$ for $\leq 1$ serving/d). Therefore, we do not consider residual confounding as the most likely explanation for our results.

Social desirability bias might have partially accounted for an apparent higher consumption of F\&V. However, to be able to explain the observed temporal trend, this social desirability bias should have increased with calendar time. We do not have any evidence to support this possibility. The criteria for admitting participants in the cohort and the recruitment strategies remained essentially the same for the SUN cohort during the assessed period. However, the adjustment for other lifestyle and sociodemographic characteristics of recruited participants renders them more comparable. In addition, in the design of the SUN cohort, our aim was not to gather a 'representative' sample in the statistical sense of being a probability sample of a target population. We intended to obtain a fairly homogenous cohort with the ability to conduct valid within-cohort comparisons. Our goal was to select a study group for homogeneity with respect to important confounders, for highly cooperative behaviour and for availability of accurate information, as recommended in epidemiological research ${ }^{(42)}$.

Taking into account these characteristics of our cohort, we acknowledge that our absolute estimates for the prevalence of low F\&V consumption would be overly optimistic to be applied to the less-educated sectors of the population and that it would be inappropriate to generalise these findings to the general Spanish population. We can only conclude that in this well-educated Mediterranean cohort the adequacy of $\mathrm{F} \& \mathrm{~V}$ consumption has improved in the past 10 years, but the room for improvement is still large.

\section{Acknowledgements}

There is no financial arrangement with any food company. All funding has been provided by the Spanish Ministry of Health and the Navarra Regional Government. The present study was supported by the Spanish Government, Instituto de Salud Carlos III (RD 06/0045, PI030678, PI042241, PI050514, PI050976, PI070240, PI081943 and PI1002293) and by the Government of Navarra (PI41/2005, PI36/2008). The authors declare that they have no conflict of interest. M.A.M.-G. had full access to all of the data in the study and takes responsibility for the integrity of the data and the accuracy of the data analysis; M.A.M.-G., C.F.-A., M.R.-C. were responsible for study concept and design; M.A.M.-G., C.F.-A., Z.V.-R. and S.B. were responsible for acquisition of data; M.A.M.-G., C.F.-A., C.L.-B., Z.V.-R., S.B. and M.R.-C. were responsible for analysis and interpretation of data; M.A.M.-G. was responsible for drafting of the manuscript; M.A.M.-G., C.F.-A., C.L.-B., Z.V.-R., S.B. and M.R.-C. were responsible for critical revision of the manuscript for important intellectual content; M.A.M.-G. and C.F.-A. were responsible for statistical analysis; M.A.M.-G. obtained funding; M.A.M.-G., C.F.-A., Z.V.-R. and S.B. were responsible for administrative, technical, or material support; M.A.M.-G., C.L.-B. and M.R.-C. were responsible for study supervision. The authors thank the participants of the SUN study for their continued cooperation and participation. The authors thank all members of the SUN Study Group (http:// www.unav.es/departamento/preventiva/quienessun).

\section{References}

1. Daar AS, Singer PA, Persad DL et al. (2007) Grand challenges in chronic non-communicable diseases. Nature 450, 494-496.

2. Krauss RM, Eckel RH, Howard B et al. (2000) AHA Dietary Guidelines: revision 2000: a statement for healthcare professionals from the Nutrition Committee of the American Heart Association. Circulation 102, 2284-2299.

3. Gidding SS, Lichtenstein AH, Faith MS et al. (2009) Implementing American Heart Association pediatric and adult nutrition guidelines: a scientific statement from the American Heart Association Nutrition Committee of the Council on Nutrition, Physical Activity and Metabolism, Council on Cardiovascular Disease in the Young, Council on Arteriosclerosis, Thrombosis and Vascular Biology, Council on Cardiovascular Nursing, Council on Epidemiology and Prevention, and Council for High Blood Pressure Research. Circulation 119, 1161-1175.

4. World Health Organization (2004) Global Strategy on Diet, Physical Activity and Health. Joint WHO/FAO Expert Consulation. Geneva: WHO. 
5. Danaei G, Ding EL, Mozaffarian D et al. (2009) The preventable causes of death in the United States: comparative risk assessment of dietary, lifestyle, and metabolic risk factors. PLoS Med 6, e1000058.

6. Martinez-Gonzalez MA (2006) The SUN cohort study (Seguimiento University of Navarra). Public Health Nutr 9, 127-131.

7. Martinez-Gonzalez MA, Sanchez-Villegas A, De Irala J et al. (2002) Mediterranean diet and stroke: objectives and design of the SUN project. Seguimiento Universidad de Navarra. Nutr Neurosci 5, 65-73.

8. Segui-Gomez M, de la Fuente C, Vazquez Z et al. (2006) Cohort profile: the 'Seguimiento Universidad de Navarra' (SUN) study. Int J Epidemiol 35, 1417-1422.

9. Martin-Moreno JM, Boyle P, Gorgojo L et al. (1993) Development and validation of a food frequency questionnaire in Spain. Int J Epidemiol 22, 512-519.

10. Fernandez-Ballart JD, Piñol JL, Zazpe I et al. (2010) Relative validity of a semi-quantitative food-frequency questionnaire in an elderly Mediterranean population of Spain. Br J Nutr 103, 1808-1816.

11. de la Fuente-Arrillaga C, Vázquez-Ruiz Z, Bes-Rastrollo M et al (2010) Reproducibility of a food frequency questionnaire (FFQ) validated in Spain. Public Health Nutr 13, 1364-1372.

12. Alonso A, Beunza JJ, Delgado-Rodríguez M et al. (2005) Validation of self reported diagnosis of hypertension in a cohort of university graduates in Spain. BMC Public Health 5, 94 .

13. Martinez-Gonzalez MA, Lopez-Fontana C, Varo JJ et al (2005) Validation of the Spanish version of the physical activity questionnaire used in the Nurses' Health Study and the Health Professionals' Follow-up Study. Public Health Nutr 8, 920-927.

14. Roman-Viñas B, Ribas Barba L, Ngo J et al. (2009) Validity of dietary patterns to assess nutrient intake adequacy. Br J Nutr 101, Suppl. 2, S12-S20.

15. Sanchez-Villegas A, Schlatter J, Ortuno F et al. (2008) Validity of a self-reported diagnosis of depression among participants in a cohort study using the Structured Clinical Interview for DSM-IV (SCID-I). BMC Psychiatr 8, 43.

16. Willett W (1998) Issues in analysis and presentation of dietary data. In Nutritional Epidemiology, 2nd ed., pp. 322 [W Willet, editor]. New York, NY: Oxford University Press.

17. Pereira MA, O'Reilly E, Augustsson K et al. (2004) Dietary fiber and risk of coronary heart disease: a pooled analysis of cohort studies. Arch Intern Med 164, 370-376.

18. Dauchet L, Amouyel P, Hercberg S et al. (2006) Fruit and vegetable consumption and risk of coronary heart disease: a meta-analysis of cohort studies. J Nutr 136, 2588-2593.

19. He FJ, Nowson CA, Lucas $M$ et al. (2007) Increased consumption of fruit and vegetables is related to a reduced risk of coronary heart disease: meta-analysis of cohort studies. J Hum Hypertens 21, 717-728.

20. Ness AR \& Powles JW (1997) Fruit and vegetables, and cardiovascular disease: a review. Int J Epidemiol 26, 1-13.

21. Dauchet L, Amouyel P \& Dallongeville J (2005) Fruit and vegetable consumption and risk of stroke: a meta-analysis of cohort studies. Neurology 65, 1193-1197.

22. He FJ, Nowson CA \& MacGregor GA (2006) Fruit and vegetable consumption and stroke: meta-analysis of cohort studies. Lancet 367, 320-326.

23. Nagura J, Iso H, Watanabe Y et al. (2009) Fruit, vegetable and bean intake and mortality from cardiovascular disease among Japanese men and women: the JACC Study. Br J Nutr 102, 285-292.
24. Takachi R, Inoue $\mathrm{M}$, Ishihara $\mathrm{J}$ et al. (2008) Fruit and vegetable intake and risk of total cancer and cardiovascular disease: Japan Public Health Center-Based Prospective Study. Am J Epidemiol 167, 59-70.

25. Cai H, Shu XO, Gao YT et al. (2007) A prospective study of dietary patterns and mortality in Chinese women. Epidemiology 18, 393-401.

26. Mizrahi A, Knekt P, Montonen J et al. (2009) Plant foods and the risk of cerebrovascular diseases: a potential protection of fruit consumption. Br J Nutr 102, 1075-1083.

27. Nakamura K, Nagata C, Oba S et al. (2008) Fruit and vegetable intake and mortality from cardiovascular disease are inversely associated in Japanese women but not in men. J Nutr 138, 1129-1134.

28. Dauchet L, Montaye M, Ruidavets JB et al. (2010) Association between the frequency of fruit and vegetable consumption and cardiovascular disease in male smokers and non-smokers. Eur J Clin Nutr 64, 578-586.

29. Hamer M \& Chida Y (2007) Intake of fruit, vegetables, and antioxidants and risk of type 2 diabetes: systematic review and meta-analysis. $J$ Hypertens 25, 2361-2369.

30. Carter P, Gray LJ, Troughton J et al. (2010) Fruit and vegetable intake and incidence of type 2 diabetes mellitus: systematic review and meta-analysis. BMJ 341, c4229.

31. Boffetta P, Wichmann J, Ferrari P et al. (2010) Fruit and vegetable intake and overall cancer risk in the European Prospective Investigation into Cancer and Nutrition (EPIC). J Natl Cancer Inst 102, 529-537.

32. Willett WC (2010) Fruits, vegetables, and cancer prevention: turmoil in the produce section. J Natl Cancer Inst 102, 510-511.

33. Riboli E \& Norat $\mathrm{T}$ (2003) Epidemiologic evidence of the protective effect of fruit and vegetables on cancer risk. $A m \mathrm{~J}$ Clin Nutr 78, Suppl. 3, S559-S569.

34. Lee JE, Mannisto S, Spiegelman D et al. (2009) Intakes of fruit, vegetables, and carotenoids and renal cell cancer risk: a pooled analysis of 13 prospective studies. Cancer Epidemiol Biomarkers Prev 18, 1730-1739.

35. World Cancer Research Fund/American Institute for Cancer Research (2007) Second Expert Report: Food, Nutrition, Physical Activity, and the Prevention of Cancer: A Global Perspective [report]. Washington, DC: AICR.

36. Nestle M (2003) Food Politics. London: University of California Press.

37. Dauchet L, Amouyel P \& Dallongeville J (2009) Fruits, vegetables and coronary heart disease. Nat Rev Cardiol 6, 599-608.

38. Hutcheon JA, Chiolero A \& Hanley JA (2010) Random measurement error and regression dilution bias. BMJ 340, c2289.

39. Hung HC, Joshipura KJ, Jiang R et al. (2004) Fruit and vegetable intake and risk of major chronic disease. $J$ Natl Cancer Inst 96, 1577-1584.

40. De Irala J, Groth M, Johansson L et al. (2000) A systematic review of socio-economic differences in food habits in Europe: consumption of fruit and vegetables. Eur J Clin Nutr 54, 706-714.

41. Roos G, Johansson L, Kasmel A et al. (2001) Disparities in vegetable and fruit consumption: European cases from the north to the south. Public Health Nutr 4, 35-43.

42. Rothman KJ, Greenland S \& Lash T (2008) Validity in epidemiologic studies. In Mod Epidemiol, 3rd ed., pp. 146 [KJ Rothman, S Greenland and T Lash, editors]. Philadelphia, PA: Lippincott Williams and Wilkins. 